\title{
Prólogo \\ Racismo en Chile: colonialismo, nacionalismo, capitalismo
}

\author{
María Emilia Tijoux Merino \\ Universidad de Chile. \\ Email: emiliatijoux@uchile.cl
}

\section{María Gabriela Córdova Rivera \\ Universidad de Los Lagos, CEDER. \\ Email: maria.cordova@ulagos.cl}

Las migraciones no son un fenómeno reciente ni localizado. Hombres y mujeres abandonan sus países buscando trabajo y supervivencia empujados por la pobreza, las guerras, los conflictos civiles y las persecuciones que ponen en peligro sus vidas. Son personas expulsadas de sus países que provienen generalmente de poblaciones empobrecidas para devenir protagonistas de las migraciones, un fenómeno sin precedentes que actualmente se produce en un contexto de total explotación dada en un siglo de mundialización globalizada, que los somete a todo tipo de violencias.

Los países receptores, buscando proteger a sus naciones y asustados por lo que consideran una "invasión", levantan muros en las fronteras e imponen medidas extremas para restringir estos desplazamientos, acrecentando el tráfico y la trata que tienen trágicas consecuencias para los inmigrantes. Estos hechos muestran la exacerbación de una de las paradojas de la modernidad- siguiendo a Bauman-, correspondiente a una cultura de "residuos humanos", que abarca toda una masa de "poblaciones superfluas" conformadas por migrantes, refugiados y otros "condenados de la tierra" (Fanon, 1961). No obstante, en este mismo marco de violencia y expulsión, el inmigrante deviene cada vez más necesario para el desarrollo de una economía global que lo demanda y lo cosifica como mano de obra que ingresa en las sociedades de destino, pero siempre desde una posición subordinada que los suma a quienes ya permanecen fuera de las ganancias de la modernidad.

La apertura democrática chilena de fines de los años noventa, convirtió a nuestro país en un lugar sentido como "el sueño chileno" de trabajadores del continente que huyendo de la pobreza o las persecuciones que llegan junto a sus familias. Chile los atrae debido a una condición económica y política divulgada como exitosa, que lo sitúa como país seguro (y cercano), logrando que estos hombres y mujeres vengan a insertarse cuando lo logran- principalmente en nichos laborales precarios. Sin embargo la sociedad chilena reacciona negativamente a sus presencias, las insti- 
tuciones los ignoran y los medios de comunicación publican constantemente su peligro, difundiendo estereotipos basados en mitos que estarían interrumpiendo las rutinas de la normalidad nacional. Los inmigrantes parecen entonces constituir la excepción construida por una política racializada que entiende a la "raza", como un sistema de diferenciaciones hechas en su nombre. Es así como la inmigración deviene pura palabra no sujeta a su propio sentido, pues no contiene a todos los inmigrantes y señala únicamente a quienes ha armado para odiar, criticar y evaluar constantemente en razón de una "raza”, clase, color y sexo, que deja ver una 'otredad' negada.

En este marco deshumanizador, miles de personas inmigrantes devienen cuerpos circulando en variados mercados que los buscan como mano de obra barata, disponible, traficable y presta a todo. Desprovistos de humanidad y de historia, de cultura e incluso de sentimientos por causa de su origen, pobreza, nacionalidad, color, apariencia, habla y/o acento, los inmigrantes son percibidos como sujetos de peligro, contaminación o infección, que no es más que el resultado de una visión anclada en la historia, generalizada y difundida que los deja permanentemente expuestos a violentos hechos de discriminación, xenofobia y racismo. Atrapados en esta paradoja que los envuelve y condena, son necesarios para un uso mercantil múltiple y diferenciado, e innecesarios cuando sus cuerpos se enferman, envejecen y devienen desechables.

Condenados a menudo a la cesantía ocasional o permanente, a viviendas precarias y peligrosas, a una explotación constante y a múltiples violencias, entre algunas de las consecuencias de una condición extrema de vida no buscada, pero causada por los mismos países que hoy los rechazan o abandonan, los inmigrantes son objeto de un racismo plural observable a nivel estructural, como en las subjetividades de la vida cotidiana en el trabajo, las escuelas, las instituciones y los barrios donde se encuentran con chilenos/as precarizados y abandonados, que los acusan de ser culpables de problemas y patologías que el capitalismo a su antojo maneja. La migración entonces, en sus dos caras, emigración/inmigración, no es más que una de las consecuencias de la barbarie capitalista actual.

Pero las razones de estas situaciones son más antiguas. En Chile como en América Latina, la cultura 'blanca' arraigada en el interés desarrollista de lo europeo, se ha definido contra un 'otro/a' no blanco, que proyecta una alteridad que actúa sobre la base de un imaginario civilizatorio y racializado, determinando comportamientos prácticos y discursivos que van desde las propuestas de asimilación como un modo de integrar y olvidar completamente los orígenes, hasta la inclusión que funciona en la exclusión. Al mismo tiempo, se discrimina, desprecia, explota -laboral y sexualmente- y se abandona, odia, expulsa y aniquila. Las dos fuentes de la constitución del "nosotros", que son el sustrato colonial y la instauración del Estado-nación, forjan un poderoso imaginario nacional que legitima la subordinación y la hegemonía, para que luego argumentaciones racistas junto a discursos y prácticas clasistas se alojen en el cuerpo nacional, 
constituyendo un habitus que contiene a este imaginario colonial-nacional clasista y racista, que ubica en posiciones inferiores a las minorías para justificar su dominación. Estamos frente a un racismo generalizado que se ha manifestado en todo el continente de modo permanente contra los pueblos originarios, naturalizando la mayoría de las veces, una diferencia que proviene de las políticas que las naciones construyen para mantener su poder, al que hoy se suma un racismo desplegado contra inmigrantes provenientes de países vecinos que gobiernos y sociedades catalogan negativamente

La literatura especializada da cuenta de las características de las personas inmigrantes, como de sus relaciones, intereses y modos en que organizan las remesas que envían a los suyos. Sabemos de la contribución que entregan a los países receptores y de los procesos de aculturación que en todas direcciones se producen y conocemos también, la folklorización y exotización que los hace objeto de reposo y distracción. Sin embargo, hay responsables mayores del sufrimiento silenciado que los inmigrantes arrastran debido a su necesidad de callar, ocultar e incluso aceptar agresiones cuando se trata de permanecer en un lugar intentando vivir y no ser expulsado o perseguido.

La sección “Lente de Aproximación” del número 42 de Polis, reúne trece artículos sobre el racismo del siglo XXI en Chile que arrastra una potente historia colonial y estatal-nacional, dada en medio de crisis mundializadas. Son muchos los cuestionamientos que involucran los derechos que puede tener un inmigrante cuando es pobre, negro, indígena, mujer, porque están en juego proyectos económicos y políticos que siguen buscando homogenizarse en torno a una figura única -la del blanco europeo-, que sigue siendo deseada. Los textos que integran esta sección monográfica, confluyen en el inconsciente colonial (Brossat, 2013) propio de las sociedades contemporáneas, colonizadoras o colonizadas, atravesadas por la presencia de una ausencia: la colonización, la colonia y el colonialismo que hoy se manifiestan para envenenar el presente.

Los artículos que presentamos, entregan diversos elementos de conocimiento sobre una historia social y política chilena de maltrato y de violencia que hoy día emerge como racismo con la llegada de personas inmigrantes de América Latina y del Caribe a Chile, dando cuenta de las responsabilidades de un Estado que produce miedo, discriminaciones, segregaciones y prácticas sociales violentas ya existentes en nuestra historia que reaparecen en las vivencias de inmigrantes obligadas al comercio sexual cuando se cierran las puertas del trabajo, en la segregación de quienes buscan techo, en la violencia del trato en las fronteras o en el abuso de los empleadores. Pero al mismo tiempo puede observarse que surgen movimientos, tácticas, resistencias o gestos que parecen conformarse como producto y a contrapelo de una exclusión permanente de estos actores de una vida de la que aprenden, para armarse de toda herramienta que les permita enfrentar la ausencia de política, de interés y de humanidad que claramente el racismo devela. 
Abre la sección del Lente de Aproximación, Ana Bengoa Valdés con su artículo De maras a marabuntas. El miedo como dispositivo gubernamental, una lectura desde EI Salvador, referido al proceso de criminalización y estigmatización de las maras, como otredades extranjeras relegadas a guetos de centroamericanos en Estados Unidos. Desde una lectura crítica, la autora aborda la violencia hacia estas organizaciones definidas como "pandillas criminales transnacionales” por las políticas y medios de comunicación, en un intento por visibilizar de qué manera son estas instituciones las que precisamente reproducen lo que “combaten”, más violencia.

El aporte de Cristián Carrère Álvarez y Michelle Carrère Álvarez, titulado Inmigración femenina en Chile y mercado de trabajos sexualizados. La articulación entre racismo y sexismo a partir de la interseccionalidad, realizado a partir del trabajo de campo en las regiones más australes del país, pone en evidencia que la sobre-representación de mujeres inmigrantes colombianas y dominicanas en el actual comercio sexual chileno, esconde relaciones sociales de poder que actualizan la condición de "hombre dominante" y de "mujer dominada", relegando las expectativas laborales reales de estas mujeres a las cuatro paredes de un night club. La categoría de "inmigrante", operaría como un estatus que entrega la vulnerabilidad objetiva necesaria para el ejercicio de dicha dominación.

Por su parte, la contribución de las investigadoras Yasna Contreras Gatica, Veera Ala-Louko y Gricel Labbé: Acceso exclusionario y racista a la vivienda formal e informal en las áreas centrales de Santiago e Iquique, revela una serie de estrategias empleadas por inmigrantes latinoamericanos tras las nuevas fronteras simbólicas y materiales en el acceso a la vivienda formal e informal en estas ciudades de destino. La condición racial y el origen del inmigrante latinoamericano (especialmente inmigrantes negros), lo conminan por restricción y limitación a la exclusión del sistema formal de acceso a la vivienda, yal creciente mercado ilegal de vivienda informal, que vulnera el derecho de todo ser humano a habitar en condiciones dignas, independientemente de su estatus de ciudadanía.

Pamela Fernández Navas, reflexiona en torno a la configuración identitaria dentro del contexto salitrero, utilizando como eje de análisis las categorías civilización/barbarie en su artículo, La otredad incivilizada en el mundo del salitre. El caso de indígenas bolivianos e inmigrantes asiáticos en Tarapacá, 1900-1910. Desde allí discute acerca del papel del racismo en la construcción social del otro y su vinculación con la identidad pampina en tiempos de ascenso del obrerismo, mediante un trabajo de archivo que devela la violencia discursiva desplegada por la prensa obrera de Tarapacá hacia indígenas bolivianos e inmigrantes asiáticos.

La sección monográfica continúa con el documento Redes de asociaciones migrantes y actores españoles: Un modelo de integración desde la capitalización social interorganizativa, de José Manuel Gaete Fiscella y Paola Andrea Ilabaca Baeza quienes presentan un modelo de integración social a nivel organizacional de las asociaciones de migrantes 
extracomunitarios en España prestando especial atención sobre el proceso de integración que alcanzan los colectivos extranjeros, en la sociedad de acogida española. Los resultados de la investigación revelan evidentes diferenciales de poder entre las partes interactuantes, lo que no deja de ser atractivo considerando que las asociaciones de migrantes suponen tanto un mecanismo de integración para los mismos migrantes como de cohesión para los nativos.

Desde otra perspectiva Dasten Julián Véjar aborda el racismo neocolonial chileno a propósito del cuerpo indígena, en su artículo titulado La huelga de hambre mapuche. Una mirada crítica a los síntomas del Estado chileno. La huelga consecuencia del ejercicio político de violencia y síntoma social del Estado, es también la forma de una subversión con su propia existencia, poder y pretensión e imposibilidad ideológica de legitimidad y universalidad. El texto se constituye en una invitación para los estudios de resistencia poscoloniales que, integrando la lógica de subordinación y dominación que prolifera en el estado moderno desde una matriz étnica-género-clase, se adentre en los procesos de resistencia y las cosmovisiones particulares de los pueblos originarios de América Latina.

A continuación, en el trabajo titulado La frontera cedazo y el desierto como aliado. Prácticas institucionales racistas en el ingreso a Chile, la investigadora Nanette Liberona Concha, observa los procedimientos respecto a los requisitos de ingreso de extranjeros al país en la frontera entre Chile y Bolivia, constatando sucesos racistas reiterados y abuso de poder por parte de funcionarios, principalmente hacia la población afrodescendiente colombiana, sino además prácticas discrecionales que contribuyen a vulnerar aún más la condición de inmigrante y al tráfico organizado de personas. Lejos de impedir el ingreso de estos extranjeros al país, estos ponen en riesgo su vida al ingresar de manera clandestina.

Sigue la contribución de Francisca Márquez y Juan José Correaque lleva por título Identidades, arraigos y soberanías. Migración peruana en Santiago de Chile, quienes a partir del análisis de relatos de vida abordan las trayectorias migratorias en atención a la construcción de identidad en origen y destino, los lazos sociales construidos en este proceso de desarraigo y los recursos culturales que por ellos circulan. La tesis que se desarrolla señala que la experiencia del des-arraigo constituye una posibilidad de fortalecimiento de los lazos sociales de los sujetos migrantes, pero a su vez de construcción siempre inacabada, de una identidad más abierta y flexible a la diferencia y la diversidad cultural.

Por su parte Andrea Riedemann y Carolina Stefoni, trasladan la discusión sobre racismo al ámbito de la educación en su artículo Sobre el racismo, su negación, y las consecuencias para una educación anti-racista en la enseñanza secundaria chilena. Las autoras abordan el racismo en la enseñanza secundaria, específicamente en un liceo de Santiago con una alta presencia de alumnos afrodescendientes provenientes de Haití. El estudio, constata una serie de experiencias de racismo y propone de manera 
concreta posibles vías para construir una educación anti-racista que sea incorporada en los lineamientos curriculares del Ministerio de Educación e involucre a los diversos estamentos del sistema educativo, partiendo por los profesores, orientadores, alumnos y apoderados.

Relacionado con lo anterior, la contribución de Nicolás Rojas Pedemonte, Nassila Amode y Jorge Vásquez Rencoret titulada Racismo y matrices de "inclusión" de la migración haitiana en Chile: elementos conceptuales y contextuales para la discusión, reflexiona acerca de las representaciones y experiencias de racismo y exclusión en relación a matrices socioculturales que los migrantes haitianos identifican como posibilidades de inserción en la sociedad chilena. Entre sus hallazgos dan cuenta de una actitud que consiste principalmente en esquivar, ignorar o justificar el racismo y sus efectos, en pos de la concreción sus objetivos migratorios: principalmente la inserción económica en la sociedad chilena.

El artículo de María Emilia Tijoux Merino y Simón Palominos Mandiola titulado Aproximaciones teóricas para el estudio de procesos de racialización y sexualización en los fenómenos migratorios de Chile, es un aporte sustantivo para el debate actual sobre las relaciones de poder que construyen categorías de raza y de género encarnadas en el cuerpo de las y los inmigrantes. Su propuesta invita a la reflexividad en el quehacer de las Ciencias Sociales y humanas que abordan la cuestión migratoria, a ampliar la interpretación interdisciplinaria respecto de los estudios de la inmigración en Chile a partir de los conceptos de racialización y sexualización los que desde sus bases teóricas y en su imprescindible articulación permiten comprender tanto los procesos de construcción de las identidades nacionales así como profundizar en la comprensión de las migraciones actuales en el país.

Cierra el Lente de Aproximación, Liván Usallán Méndez con el documento El pluralismo cultural y la gestión política de la inmigración en Chile: ¿ausencia de un modelo? Referido al análisis sobre las principales características del paradigma del asimilacionismo y del paradigma del pluralismo cultural desde una perspectiva de gestión de la diversidad en sociedades multiculturales. Desde allí, traslada la discusión teórica al examen del marco normativo desarrollado por el Estado chileno en materia de migración para determinar el paradigma de gestión predominante en el mismo.

Se completa este número de Polis con la sección Propuestas y avances de investigación, la cual incluye un total de diez artículos, para finalizar la actual edición con el apartado Comentarios y reseñas de libros en donde se incluyen cuatro textos. 


\section{Bibliografia}

Bauman, Zygmunt (2007), Le preìsent liquide: peurs sociales et obsession seìcuritaire, Seuil, Paris.

Brossat, Alain (2013), Autochtone imaginaire. Etranger imaginé. Retours sus la xénofobie ambiante. Ed. Du Souffle, Paris.

Fanon, Frantz (1961) (2002), Les damnés de la terre, Ed. La Découverte, París. 